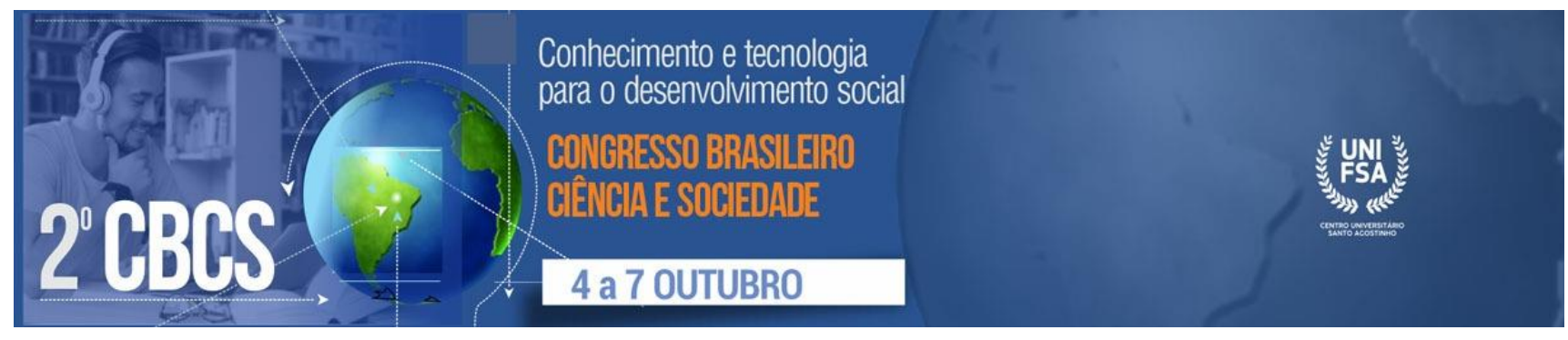

\title{
RELAÇÃO ENTRE COVID-19, OBESIDADE E À AMPLIFICAÇÃO DA RESPOSTA INFLAMATÓRIA NO TECIDO ADIPOSO: REVISÃO INTEGRATIVA ${ }^{1}$
}

\author{
Stálin Santos Damasceno/UESPI ${ }^{2}$ \\ Damião Pires de Sá/UESPI ${ }^{3}$ \\ Fabrício Pires de Moura do Amaral/UESPI ${ }^{4}$ \\ Dario Brito Calçada/UESPI ${ }^{5}$
}

\begin{abstract}
RESUMO
A inflamação crônica causada pelo COVID-19, prejudica a sinalização da insulina nos adipócitos, resultando em uma resistência à insulina e contribuindo para o desenvolvimento de distúrbios metabólicos que afetam adversamente o prognóstico dos pacientes com COVID-19. Esta pesquisa teve como objetivo investigar a relação entre COVID-19, obesidade e amplificação da resposta inflamatória no tecido adiposo, na população com diagnóstico positivo para o novo coronavírus. Trata-se de uma revisão integrativa realizada nas bases Scielo; LILACS; PubMed e BDEnf. Dos 151 estudos rastreados, 15 foram selecionados. Todos os estudos apresentados apontam que a obesidade é um dos mais importantes e mais prevalentes fator de risco para o acometimento e agravamento do COVID 19 na população, especialmente associado a resposta infamatória no tecido adiposo. Mais estudos sobre essa temática devem ser estimulados pois podem auxiliar na estimativa de qual paciente é potencialmente propenso aos desfechos ruins da COVID relacionada a obesidade.
\end{abstract}

Palavras-Chave: COVID-19. SARS CoV-2. Obesity. Inflammatory Response.

\section{INTRODUÇÃO}

Segundo Celuppi, lanka Cristina et al (2021), a pandemia da COVID-19 é considerada uma emergência de saúde pública internacional, principalmente pelas características como a qual vem se desenvolvendo desde março de 2020, infectando pessoas e se alastrando por todo

\footnotetext{
${ }^{1}$ Trabalho apresentado no 20 Congresso Brasileiro Ciência e Sociedade (CBCS 2021), promovido pelo Centro Universitário Santo Agostinho, de 04 a 07 de outubro de 2021, em Teresina-PI.

${ }^{2}$ Stálin Santos Damasceno. Especialista em Gestão em Saúde. Universidade Estadual do Piauí-UESPI, Brasil.

${ }^{3}$ Damião Pires de Sá. Mestrando em Biotecnologia em Saúde Humana e Animal. Universidade estadual do Piauí-UESPI, Brasil.

${ }^{4}$ Fabrício Pires de Moura do Amaral. Doutor em Farmacologia. Universidade Estadual do Piauí-UESPI, Brasil

${ }^{5}$ Dario Brito Calçada. Doutor em Ciências da Computação e Matemática Computacional. Universidade Estadual do Piauí, Brasil.
} 
o mundo, o número de casos confirmados ultrapassa 44 milhões no mundo, com mais de 1 milhão de mortes. No Brasil, já são mais de 5 milhões casos confirmados, com mais de 150 mil mortes causadas pela doença.

Uma das principais características da COVID-19, é a sua potencialidade em desenvolver síndrome respiratória aguda grave, coronavírus-2 (SARS-CoV-2), desta forma, favorecendo dentre outros agravos a saúde, a dificuldade respiratória, podendo em muitos casos os pacientes, necessitarem de suporte de oxigênio. Nota-se que o SARS-CoV-2 difere dos coronavírus que causaram síndrome respiratória aguda grave (SARS-CoV) zoonótico em 2002 e síndrome respiratória do Oriente Médio (MERS-CoV) em 2012, (BADAWI, et al., 2016)o SG, 2016).

Diante disso, houve a necessidade de se aprofundar em pesquisas acerca do tema, para analisar o que já tem publicado e o valor dessa contribuição para o cenário científico. 0 problema norteador da pesquisa foi: Qual a relação entre as consequências geradas pela COVID-19 e a obesidade? É de extrema importância aprofundar nesta temática, pois servirá de subsídios para orientar políticas públicas, voltadas para o assistencialismo a pacientes com COVID-19 associadas a sobrepeso, obesidade e massa gorda. Pesquisas exploratórias evidenciaram que indivíduos com sobrepeso (obesidade) podem ser mais vulneráveis a complicações graves do COVID-19, em consequência do aumento do risco de doenças crônicas desencadeadas pela a obesidade. Razões para explicar esse fato, ainda precisam ser mais estudadas, porém infere-se que a inflamação crônica seja uma das causas (CHIAPPETTA S, et al., 2020).

Segundo Kim J, et al. (2020), a obesidade constitui-se um estado de inflamação sistêmica crônica de baixo grau, tendo como característica o aumento da secreção de citocinas próinflamatórias do tecido adiposo e a infiltração de leucócitos, incluindo macrófagos. Sendo assim, essa inflamação crônica causada pela COVID-19, prejudica a sinalização da insulina nos adipócitos, resultando em uma resistência à insulina e contribuindo para o desenvolvimento de distúrbios metabólicos, como doenças cardiovasculares, diabetes tipo 2 e hipertensão, que integram o conjunto de comorbidades que afetam adversamente o prognóstico dos pacientes. Este trabalho apresenta como objetivo investigar a relação entre a COVID-19, obesidade e amplificação da resposta inflamatória no tecido adiposo, na população com diagnóstico positivo para o novo coronavírus. 


\section{METODOLOGIA}

Esta pesquisa trata-se de um levantamento e revisão integrativa da literatura, desenvolvido com estudos publicados nas bases: ScIELO; LILACS; PubMed e BDEnf, que evidenciam a relação entre a COVID-19 e o aumento da resposta inflamatória, assim como o seu prolongamento em pacientes obesos, tendo como descritores: COVID-19 and sars cov-2 and obesity and inflammatory response.

A revisão sistemática é um método que auxilia aos pesquisadores a obtenção de respostas a uma pergunta específica e utiliza técnicas explícitas e sistemáticas para identificar, selecionar e avaliar criticamente estudos relacionado a questão de busca, enquanto a revisão integrativa tem uma busca mais ampla de estudos sobre um tema. Nessa pesquisa, o recorte temporal abrangeu artigos publicados no período mais recente possível, embora exista na literatura artigos que relatam a associação do aumento da resposta inflamatória no tecido adiposo com algumas doenças virais, não especificamente a COVID-19, isso não se tornou um critério de inclusão.

Em uma das etapas de seleção dos artigos, os mesmos foram selecionados por meio da análise dos títulos, dos resumos, da metodologia e o texto na íntegra. Foram considerados artigos escritos em qualquer idioma, disponíveis na íntegra e que contemplavam o tema e os objetivos da revisão. Foram critérios de exclusão: artigos publicados antes de 2015, trabalhos duplicados e artigos de revisão.

Por intermédio da busca realizada nas bases de dados, foram encontrados 151 artigos, sendo 71 trabalhos relacionados aos descritores: COVID-19 and sars cov-2 and obesity and inflammatory response. Dos artigos que possuíam as palavras-chave, 30 (trinta) artigos foram excluídos por se tratarem de revisão, 80 (oitenta) artigos não foram incluídos pois não havia nenhuma relação com o tema abordado e também foram excluídos mais 6 (seis) artigos, por duplicidade, totalizando 15 artigos, o que representa 9,9\% do total.

\section{RESULTADOS E DISCUSSÃO}

Com base nos descritores utilizados, foi elaborado o quadro 01 a fim de evidenciar os estudos selecionados segundo suas características bibliométricas: autores, ano, título, objetivos, desenho do estudo e coleta de dados. Os critérios adotados consideraram a 
importância e a relevância de cada pesquisa relacionada ao relacionamento de fatores de risco, como obesidade, em pacientes positivos para a COVID-19.

Quadro 01. Caracterização dos estudos selecionados segundo caraterísticas bibliométricas, 2021.

\begin{tabular}{|c|c|c|c|c|}
\hline Autores, ano & Título & Objetivos & $\begin{array}{c}\text { Desenho do } \\
\text { Estudo }\end{array}$ & Coleta de Dados \\
\hline $\begin{array}{l}\text { Foulkes AS et } \\
\text { al., } 2021 .\end{array}$ & $\begin{array}{l}\text { Understanding the link } \\
\text { between obesity and } \\
\text { severe COVID-19 } \\
\text { outcomes: Causal } \\
\text { mediation by systemic } \\
\text { inflammatory } \\
\text { response. }\end{array}$ & $\begin{array}{l}\text { Avaliar o papel mediador } \\
\text { da inflamação sistêmica } \\
\text { nos desfechos COVID-19 } \\
\text { associados à obesidade. }\end{array}$ & $\begin{array}{l}\text { Baseado em } \\
\text { hospital, estudo } \\
\text { observacional. }\end{array}$ & $\begin{array}{l}\text { Registros de } \\
\text { pacientes internados } \\
\text { MGH COVID-19 } \\
\text { (armazenados em } \\
\text { um banco de dados } \\
\text { da Instituição). }\end{array}$ \\
\hline $\begin{array}{l}\text { McGovern J } \\
\text { et al., } 2021 .\end{array}$ & $\begin{array}{l}\text { Relation Between Body } \\
\text { Composition, } \\
\text { Systemic Inflammatory } \\
\text { Response, and Clinical } \\
\text { Outcomes in Patients } \\
\text { Admitted to an Urban } \\
\text { Teaching Hospital with } \\
\text { COVID-19 }\end{array}$ & $\begin{array}{l}\text { Examinar a relação entre } \\
\text { as medidas de tomografia } \\
\text { computadorizada de } \\
\text { composição corporal (CT- } \\
\text { BC), inflamação sistêmica } \\
\text { e desfechos clínicos em } \\
\text { pacientes com COVID-19. }\end{array}$ & $\begin{array}{l}\text { Estudo } \\
\text { protocolado. }\end{array}$ & 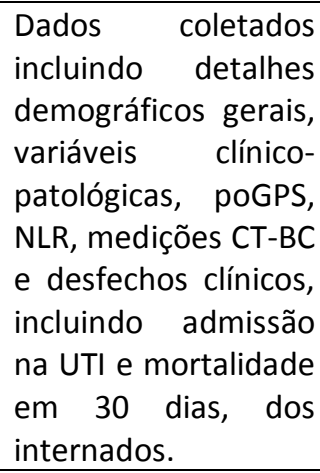 \\
\hline $\begin{array}{l}\text { Santos E Silva } \\
\text { JC., et al } \\
2021 .\end{array}$ & $\begin{array}{l}\text { Gene signatures of } \\
\text { autopsy lungs from } \\
\text { obese patients with } \\
\text { COVID-19 }\end{array}$ & $\begin{array}{l}\text { Analisar sobre o impacto } \\
\text { da obesidade nos } \\
\text { pulmões de pacientes } \\
\text { com COVID-19. }\end{array}$ & $\begin{array}{l}\text { Estudo coorte } \\
\text { controle. }\end{array}$ & $\begin{array}{l}\text { Analisamos perfis de } \\
\text { expressão gênica de } \\
\text { pulmões de autópsia } \\
\text { de uma coorte de } 14 \\
\text { pacientes } \\
\text { COVID-19 e } \\
\text { indivíduos controle. }\end{array}$ \\
\hline $\begin{array}{l}\text { Le Guen CL., } \\
\text { et al } 2021 .\end{array}$ & $\begin{array}{l}\text { COVID-19 patients } \\
\text { with obesity at risk for } \\
\text { worse outcomes } \\
\text { despite } \\
\text { younger age and fewer } \\
\text { inflammatory } \\
\text { derangements }\end{array}$ & $\begin{array}{l}\text { Descrever } \\
\text { manifestação, o curso } \\
\text { clínico e o meio de } \\
\text { biomarcadores } \\
\text { inflamatórios da COVID- } \\
19 \text { em pacientes com } \\
\text { obesidade. }\end{array}$ & $\begin{array}{l}\text { Estudo de coorte } \\
\text { retrospectivo e } \\
\text { observacional. }\end{array}$ & $\begin{array}{l}\text { Prontuário eletrônico } \\
\text { e dados e } \\
\text { laboratoriais. }\end{array}$ \\
\hline $\begin{array}{l}\text { Frasca D., et } \\
\text { al } 2021 .\end{array}$ & $\begin{array}{l}\text { Influence of obesity on } \\
\text { serum levels of SARS- } \\
\text { CoV-2-specific } \\
\text { antibodies in COVID-19 } \\
\text { patients. }\end{array}$ & $\begin{array}{l}\text { avaliar a influência da } \\
\text { obesidade, uma condição } \\
\text { associada à inflamação } \\
\text { sistêmica crônica, na } \\
\text { secreção de anticorpos } \\
\text { IgG específicos para SARS- } \\
\text { CoV-2 no sangue de } \\
\text { pacientes com COVID-19 }\end{array}$ & $\begin{array}{l}\text { Estudo } \\
\text { experimental. }\end{array}$ & $\begin{array}{lr}\text { Amostras de swab } \\
\text { nasofaríngeo r e } \\
\text { anticorpos séricos } \\
\text { positivos por } \\
\text { imunoensaio de fluxo } \\
\text { lateral (LFIA) usando } \\
\text { o dispositivo de fluxo } \\
\text { lateral (LFD) } \\
\end{array}$ \\
\hline $\begin{array}{l}\text { McNeill JN., } \\
\text { et al } 2021 .\end{array}$ & $\begin{array}{l}\text { The role of obesity in } \\
\text { inflammatory markers } \\
\text { in COVID-19 patients }\end{array}$ & $\begin{array}{lr}\text { Avaliar os marcadores } \\
\text { inflamatórios } \\
\text { indivíduos obesos e não } \\
\text { obesos hospitalizados por } \\
\text { COVID-19 no } \\
\text { Massachusetts General } \\
\text { Hospital. }\end{array}$ & $\begin{array}{l}\text { Estudo } \\
\text { observacional }\end{array}$ & $\begin{array}{l}\text { Revisão } \\
\text { prontuários. }\end{array}$ \\
\hline
\end{tabular}




\begin{tabular}{|c|c|c|c|c|}
\hline $\begin{array}{l}\text { De Lorenzo } \\
\text { A., et al } 2020 .\end{array}$ & $\begin{array}{lr}\text { Fat mass } & \text { afects } \\
\text { nutritional } & \text { status } \\
\text { of ICU } & \text { COVID-19 } \\
\text { patients } & \end{array}$ & $\begin{array}{l}\text { Avaliar a relação entre o } \\
\text { percentual de massa } \\
\text { gorda (FM\%) e a resposta } \\
\text { imunoinflamatória, após } \\
10 \text { dias em Unidade de } \\
\text { Terapia Intensiva (UTI). }\end{array}$ & $\begin{array}{l}\text { Estudo } \\
\text { prospectivo } \\
\text { observacional }\end{array}$ & $\begin{array}{lr}\text { Os } & \text { pacientes } \\
\text { recrutados } & \text { neste } \\
\text { estudo } & \text { foram } \\
\text { categorizados em } & \text { em } \\
\text { dois conjuntos: } \\
\text { "magros" } \\
\text { "obesos" de acordo } \\
\text { com o\% FM e idade, } \\
\text { com base nos } \\
\text { critérios } \\
\text { apresentados por De } \\
\text { Lorenzo }\end{array}$ \\
\hline $\begin{array}{l}\text { Almerie MQ., } \\
\text { et al } 2020 .\end{array}$ & $\begin{array}{l}\text { The association } \\
\text { between obesity and } \\
\text { poor outcome after } \\
\text { COVID-19 indicates a } \\
\text { potential therapeutic } \\
\text { role for montelukast }\end{array}$ & $\begin{array}{l}\text { Observar se o } \\
\text { montelucaste reduzirá a } \\
\text { gravidade dos danos } \\
\text { multiorgânicos } \\
\text { imunomediados } \\
\text { resultantes de COVID-19, } \\
\text { particularmente em } \\
\text { pacientes com obesidade } \\
\text { central e síndrome } \\
\text { metabólica. }\end{array}$ & Estuds in silico & $\begin{array}{lr}\text { Os autores } \\
\text { examinaram } \\
\text { medicamentos } \\
\text { aprovados de um } \\
\text { subconjunto do } \\
\text { banco de dados ZINC } \\
\text { que contém } 2.924 \\
\text { compostos. Eles } \\
\text { também examinaram } \\
\text { um banco de dados } \\
\text { de produtos naturais } \\
\text { de } 1.066 \text { produtos } \\
\text { químicos separados } \\
\text { de ervas tradicionais } \\
\text { chinesas e } 78 \\
\text { medicamentos } \\
\text { antivirais } \\
\text { conhecidos. }\end{array}$ \\
\hline $\begin{array}{l}\text { Chiappetta S., } \\
\text { et al } 2020 .\end{array}$ & $\begin{array}{l}\text { COVID-19 and the role } \\
\text { of chronic } \\
\text { inflammation in } \\
\text { patients with obesity. }\end{array}$ & $\begin{array}{l}\text { Comparar diferentes } \\
\text { procedimentos } \\
\text { bariátricos relativos aos } \\
\text { seus efeitos sobre os } \\
\text { marcadores } \\
\text { inflamação a curto e } \\
\text { longo prazo e foi } \\
\text { conduzido de acordo com } \\
\text { os princípios da } \\
\text { Declaração de Helsinque. }\end{array}$ & Ensaios clínicos & $\begin{array}{l}\text { Coleta de dados } \\
\text { demográficos e os } \\
\text { valores laboratoriais. }\end{array}$ \\
\hline $\begin{array}{l}\text { Razavi AC., et } \\
\text { al } 2020 .\end{array}$ & $\begin{array}{l}\text { A 23-Year-Old Man } \\
\text { With Multisystem } \\
\text { Inflammatory } \\
\text { Syndrome After Mild } \\
\text { COVID-19 }\end{array}$ & $\begin{array}{l}\text { Apresentar o caso de um } \\
\text { paciente jovem obeso } \\
\text { com COVID-19 recente } \\
\text { (doença coronavírus } \\
\text { 2019) que desenvolveu } \\
\text { síndrome inflamatória } \\
\text { multissistêmica (SIM) } 1 \\
\text { mês após resolução } \\
\text { espontânea }\end{array}$ & Relato de caso & $\begin{array}{l}\text { Dados clinico } \\
\text { epidemiológicos e } \\
\text { laboratoriais. }\end{array}$ \\
\hline $\begin{array}{l}\text { Bruno Pereira } \\
\text { Nunes et al., } \\
2020\end{array}$ & $\begin{array}{l}\text { Multimorbidade } \\
\text { população em risco } \\
\text { para COVID-19 grave } \\
\text { no Estudo Longitudinal } \\
\text { da Saúde dos Idosos } \\
\text { Brasileiros. }\end{array}$ & $\begin{array}{l}\text { Medir a ocorrência de } \\
\text { multimorbidade e estimar } \\
\text { o número de indivíduos } \\
\text { na população brasileira } \\
\text { com } 50 \text { anos ou mais em } \\
\text { risco para COVID-19 } \\
\text { grave. }\end{array}$ & $\begin{array}{l}\text { Estudo } \\
\text { transversal de } \\
\text { base nacional } \\
\text { com dados do } \\
\text { Estudo } \\
\text { Longitudinal da } \\
\text { Saúde dos Idosos } \\
\text { Brasileiros (ELSI- } \\
\text { Brasil) }\end{array}$ & $\begin{array}{l}\text { Roteiro semi- } \\
\text { estruturado, } \\
\text { questionário. }\end{array}$ \\
\hline
\end{tabular}




\begin{tabular}{|c|c|c|c|c|}
\hline $\begin{array}{l}\text { James } \\
\text { Macinko et } \\
\text { al., } 2020 .\end{array}$ & $\begin{array}{lr}\text { Prevalência } & \mathrm{e} \\
\text { características } & \text { de } \\
\text { brasileiros com } 50 \\
\text { anos ou mais que } \\
\text { receberam um } \\
\text { diagnóstico médico de } \\
\text { COVID-19: iniciativa } \\
\text { ELSI-COVID-19 }\end{array}$ & $\begin{array}{l}\text { Elucidar os aspectos } \\
\text { Sociais e biológicos do } \\
\text { envelhecimento. }\end{array}$ & $\begin{array}{l}\text { Estudo } \\
\text { Longitudinal da } \\
\text { Saúde dos Idosos } \\
\text { Brasileiros (ELSI- } \\
\text { Brasil) }\end{array}$ & $\begin{array}{l}\text { Entrevista telefônica } \\
\text { curta de } 5 \text { minutos de } \\
\text { duração, inquérito } \\
\text { telefônico. }\end{array}$ \\
\hline $\begin{array}{l}\text { Eurídice } \\
\text { Martínez } \\
\text { Steelel, et al., } \\
2020 .\end{array}$ & $\begin{array}{l}\text { Mudanças alimentares } \\
\text { na coorte NutriNet } \\
\text { Brasil durante a } \\
\text { pandemia de covid-19 }\end{array}$ & $\begin{array}{l}\text { Descrever características } \\
\text { da alimentação dos } \\
\text { participantes da coorte } \\
\text { NutriNet Brasil } \\
\text { imediatamente antes e na } \\
\text { vigência da pandemia de } \\
\text { covid-19. }\end{array}$ & $\begin{array}{l}\text { Estudo } \\
\text { coorte. }\end{array}$ & $\begin{array}{l}\text { Entrevista, } \\
\text { questionário } \\
\text { simplificado. }\end{array}$ \\
\hline $\begin{array}{l}\text { Fernando } \\
\text { Mejía, et al., } \\
2020 .\end{array}$ & $\begin{array}{l}\text { Características clínicas } \\
\text { y factores asociados a } \\
\text { mortalidad en } \\
\text { pacientes adultos } \\
\text { hospitalizados por } \\
\text { COVID-19 en un } \\
\text { hospital público de } \\
\text { Lima, Perú. }\end{array}$ & $\begin{array}{l}\text { Identificar características } \\
\text { clínicas e fatores } \\
\text { associados à mortalidade } \\
\text { em pacientes adultos } \\
\text { hospitalizados por } \\
\text { COVID-19 em um hospital } \\
\text { público em Lima, Peru. }\end{array}$ & $\begin{array}{l}\text { Coorte } \\
\text { retrospectiva da } \\
\text { revisão de } \\
\text { históricos } \\
\text { clínicos de } \\
\text { pacientes } \\
\text { adultos } \\
\text { internados por } \\
\text { COVID-19, entre } \\
\text { março e junho de } \\
\text { 2020, no } \\
\text { Hospital } \\
\text { Cayetano } \\
\text { Heredia, Lima- } \\
\text { Peru }\end{array}$ & $\begin{array}{l}\text { Revisão dos } \\
\text { prontuários de } \\
\text { pacientes adultos } \\
\text { internados por } \\
\text { COVID-19 no Hospital } \\
\text { Cayetano Heredia } \\
\text { (HCH). }\end{array}$ \\
\hline $\begin{array}{l}\text { Bruno Pereira } \\
\text { Nunes, et al., } \\
2020 .\end{array}$ & $\begin{array}{l}\text { Envelhecimento, } \\
\text { multimorbidade e risco } \\
\text { para COVID-19 grave: } \\
\text { ELSI-Brasil }\end{array}$ & $\begin{array}{l}\text { Medir a ocorrência de } \\
\text { multimorbidade e estimar } \\
\text { o número de } \\
\text { indivíduos na população } \\
\text { brasileira com } 50 \text { anos ou } \\
\text { mais em risco para } \\
\text { COVID-19 grave. }\end{array}$ & $\begin{array}{l}\text { Estudo } \\
\text { Transversal. }\end{array}$ & $\begin{array}{l}\text { Utilizando dados da } \\
\text { linha de base do } \\
\text { Estudo Longitudinal } \\
\text { da Saúde dos Idosos } \\
\text { Brasileiros (ELSI), } \\
\text { conduzido em 2015- } \\
2016 \text {, com } 9.412 \\
\text { indivíduos com } 50 \\
\text { anos ou mais. }\end{array}$ \\
\hline
\end{tabular}

Embora seja uma doença nova no campo da pesquisa clínica e ainda não haver um consenso, muito já se sabe sobre a COVID-19, principalmente quando se trata de fatores de risco a ela relacionada. Estudos experimentais devem ser incentivados, políticas públicas em saúde devem ser incrementadas, para que seja possível a institucionalização de diretrizes terapêuticas que sirvam de subsídios para a prática do profissional em saúde. Dentre outros fatores, a COVID-19, têm mostrado uma forte ligação entre a obesidade e a gravidade da infecção pela COVID-19, mesmo na ausência de outras comodidades.

Muito se tem avançado em estudo e conhecimento acerca dos efeitos da COVID-19 no corpo humano, Caci et al (2020), em seus estudos relata a existência de evidências emergentes de que o sobrepeso e a obesidade predispõem a sintomas graves e prognósticos negativos, 
evidenciando a gravidade aumentada da COVID-19 em relação ao aumento do índice de massa corporal.

Foi realizada uma coorte retrospectiva a partir da revisão dos prontuários de pacientes adultos internados por COVID-19, entre março e junho de 2020, no Hospital CayetanoHeredia, Lima-Peru. Foram analisados 369 prontuários, 241 (65,31\%) pacientes eram do sexo masculino e a mediana da idade foi de 59 anos (IQR: 49-68). 68,56\% apresentavam pelo menos uma comorbidade, sendo as mais frequentes obesidade (42,55\%), diabetes mellitus $(21,95 \%)$ e hipertensão arterial (21,68\%) (MEJIA et al, 2020).

Estudos demonstram substancialmente, que a doença do novo coronavírus (COVID-19) apresenta um risco particular para pessoas que possuem doenças pré-existentes, como obesidade, prejudicando a resposta imune ou amplificando a resposta pró-inflamatória. 0 estudo desenvolvido por Nunes et al (2020) foi realizado com a população de 50 anos ou mais, entre os anos de 2015 e 2016, e os dados foram coletados mediante os resultados da linha de base do Estudo longitudinal da Saúde dos Idosos Brasileiros (ELSI-Brasil). O qual identificou alguns fatores de risco relacionados ao COVID-19, dentre eles pode-se citar a obesidade, não diferindo muito dos resultados de alguns trabalhos realizados posteriormente.

Um estudo de coorte retrospectivo, com 600 pacientes positivos para COVID-19 que foram estratificados pela classe de obesidade da Organização Mundial da Saúde (OMS) e seus sintomas de apresentação, biomarcadores de doença, dados demográficos e resultados (taxa de intubação, admissão à unidade de terapia intensiva [UTI], tempo de internação [LOS] e mortalidade) foram investigados. Pacientes com obesidade eram mais propensos a comparecer ao hospital em uma idade mais jovem, com níveis reduzidos de distúrbios de biomarcadores relacionados a COVID-19 e maiores taxas de permanência e internação na UTI, embora não apresentassem risco aumentado de mortalidade (LE GUEN, 2021).

Outro trabalho importante foi o relato de caso de um paciente jovem obeso com COVID19 recente, que desenvolveu síndrome inflamatória multissistêmica (SIM) 1 mês após resolução espontânea. Um homem afro-americano de 23 anos foi admitido com uma história de 1 semana de agravamento da fadiga, mialgias, cefaleia e dispneia. O paciente foi então tratado empiricamente para MIS com imunoglobulina intravenosa e metilprednisolona, o que levou a uma rápida resolução da febre e anormalidades laboratoriais. Este caso destaca que o MIS associado ao COVID-19 pode se manifestar em pacientes acima de 21 anos e pode ocorrer com 
um início tardio após doença leve naqueles sem necessidade prévia de oxigênio ou hospitalização durante a infecção por SARS-CoV-2 (RAZAVI et al, 2020).

Segundo Chiappetta et al (2020), em seu estudo, ao analisar um grupo de pacientes metabólicos com obesidade (EOSS 2 e 3), observou um aumento da interleucina - 6 e análise de regressão linear mostrou uma correlação positiva com a proteína $C$ reativa $(P C R)(p=0,014)$ e razão cintura-quadril (RCQ) $(p=0,031)$. A identificação precoce de uma possível hiperinflamação pode ser fundamental e deve orientar a tomada de decisão quanto a hospitalização, suporte respiratório precoce e terapia com imunossupressão para melhorar a mortalidade.

É de conhecimento que a infecção pelo vírus SARS CoV-2 desencadeia uma resposta imune desproporcional, causando uma lesão sistêmica devastadora, particularmente em indivíduos com obesidade. As células imunológicas se acumulam no tecido adiposo visceral e, juntamente com os adipócitos parácrinos, liberam uma gama de citocinas biologicamente ativas (incluindo IL-1B, IL-5, IL-6 e IL-8) que podem resultar em inflamação local, pulmonar e sistêmica (ALMERIE et al, 2020).

Outro estudo mais específico foi o de De Lorenzo et al (2020), constituindo o primeiro estudo avaliando a massa gorda FM\% em pacientes COVID-19, sublinhando as características dos obesos com provável prognóstico desfavorável e o importante erro de classificação da obesidade. O número não desprezível de pacientes com IMC normal pode realmente ter um excesso de tecido adiposo e, portanto, ter um resultado desfavorável, como obeso. Neste estudo prospectivo observacional de 22 pacientes adultos afetados por pneumonia pela COVID19 e admitidos na UTI, ao invés de considerar apenas o IMC, os pacientes recrutados neste estudo foram categorizados em dois conjuntos magros os obesos de acordo com o\% FM e idade.

O estudo de McNeill et al (2021), que incluíram em sua pesquisa 781 pacientes hospitalizados com COVID-19, confirmado por PCR, admitidos no Massachusetts General Hospital de 28 de fevereiro a 27 de abril de 2020, concluíram que 349 eram obesos (45\%). Os indivíduos obesos apresentaram níveis iniciais mais elevados de proteína C reativa e ESR, velocidade dê hemossedimentação, após a contabilização de potenciais fatores de confusão em análises multivariadas ( $p<0,01$ para ambos).

O pico PCR e ESR permaneceram maiores nos obesos, além do pico D-dímero. Este estudo evidenciou, que os indivíduos obesos tiveram uma chance maior de necessitar de vasopressor, desenvolvendo insuficiência respiratória hipoxemica e morte, dentro de 28 dias 
da apresentação ao atendimento. Os principais achados foram: a) A obesidade está relacionada a uma maior inflamação, evidenciada por PCR e VHS iniciais e de pico mais elevados e D-dímero de pico; b) A obesidade está associada a maior gravidade da doença COVID-19, incluindo maior probabilidade de uso de vaso opressor, insuficiência respiratória hipoxemica e morte; c) Níveis basais mais elevados de PCR e D-dímero estão associados a piores desfechos clínicos, mesmo após ajuste para IMC, sugerindo assim que a maior gravidade da doença indivíduos obesos é caracterizada por inflamação mais exuberante.

Segundo Foulkes et al (2021), um estudo observacional demonstrou que a obesidade foi associada a maior probabilidade de ventilação ou morte $[O R=1,73$, IC $95 \%=(1,25,2,41), p=$ $0,001]$ e pico de PCR mais alto $(p<0,001)$ em comparação com pacientes não obesos. $A$ proporção estimada da associação entre obesidade e ventilação ou morte mediada pela PCR foi de 0,49 ( $p<0,001)$. A evidência de mediação foi mais pronunciada em pacientes $<65$ anos [proporção mediada $=0,52(p<0,001)$ versus $0,44(p=0,180)$ ]. Os resultados foram mais moderados, mas consistentes para o pico de ESR. A mediação por outros marcadores inflamatórios não foi suportada. Os resultados foram replicados na coorte CUIMC / NYP ( $n=$ 2626). Esses resultados revelam oportunidade terapêutica para direcionar as vias inflamatórias sistêmicas e monitorar intervenções em subgrupos de alto risco e, particularmente, em pacientes obesos.

Outro estudo relevante que podemos destacar é o de Frasca et al (2021), os autores deste trabalho avaliaram a influência da obesidade, como uma condição associada a inflamação sistêmica crônica, na secreção de anticorpos IgG específicos para SARS CoV-2, no sangue de pacientes com COVID-19, confirmando que a obesidade está associada a quantidades reduzidas de anticorpos IgG específicos no organismo.

O estudo de McGovern J (2021), teve como objetivo examinar a relação entre as medidas de tomografia computadorizada de composição corporal (CT-BC), inflamação sistêmica e desfechos clínicos em pacientes com COVID-19. A população foi os pacientes que se apresentaram na instituição entre 17 de março e 10 de maio de 2020, com um teste de PCR positivo para COVID-19 ou alterações radiológicas características. Os dados coletados incluíram detalhes demográficos gerais, variáveis clínico-patológicas, poGPS, NLR, medições CT-BC e desfechos clínicos, incluindo admissão na UTI e mortalidade em 30 dias, dos internados. Sessenta e três pacientes preencheram os critérios de inclusão do estudo. Quarenta e dois pacientes $(67 \%)$ tinham idade $\geq 70$ anos, $30(47,6 \%)$ eram do sexo masculino e $34,9 \%(n=22)$ 
tinham poGPS $\geq 1$. A admissão ITU foi significativamente associada a um alto VFA $(P<0,05)$. A mortalidade em 30 dias foi associada com alto VFA $(P<0,05)$ e baixo SMI $(P<0,05)$.

Um estudo que analisou perfis de expressão gênica de pulmões de autópsia de uma coorte de 14 pacientes com COVID-19 e 4 indivíduos controle. Os pacientes foram divididos em 3 grupos de acordo com suas comorbidades: hipertensão, diabetes tipo 2 (DM2) e obesidade. Em seguida, identificamos as alterações moleculares associadas a essas comorbidades em pacientes com COVID-19. Pacientes apenas com hipertensão apresentaram níveis mais elevados de genes inflamatórios e genes relacionados às células B quando comparados àqueles com DM2 e obesidade. No entanto, os níveis de IFN-gama, IL22 e CD274 (um ligante que se liga ao receptor PD1) foram maiores em pacientes COVID-19 com DM2 e obesidade. Vários genes associados ao metabolismo e ao sistema imunológico, como G6PD, LCK e IL10, foram significativamente induzidos nos pulmões do grupo de obesos. Nossos resultados sugerem que a infecção por SARS-CoV-2 nos pulmões pode exacerbar a resposta imune e a condição crônica em pacientes obesos com COVID-19 (SANTOS e SILVA, 2021).

Segundo Steele et al (2020), a ingestão de alimentos ultraprocessados nas regiões economicamente menos desenvolvidas e por pessoas com menor escolaridade preocupa, pois eleva o risco de obesidade, hipertensão e diabetes, cuja presença aumenta a gravidade e a letalidade da covid-19. A obesidade foi quase duas vezes mais prevalente entre aqueles que relataram um diagnóstico positivo para COVID-19 (MACINKO et al, 2020).

\section{CONSIDERAÇÕES FINAIS/CONCLUSÕES}

Todos os estudos apresentados apontam que a obesidade é um dos mais importantes e mais prevalentes fatores de risco para o acometimento e agravamento do COVID-19 na população, especialmente associado a resposta infamatória no tecido adiposo. Mais estudos sobre essa temática devem ser estimulados, pois estes, podem auxiliar na estimativa de qual paciente é potencialmente propenso aos desfechos ruins da COVID-19 relacionada a obesidade, além de estimular medidas de saúde pública para a população.

\section{REFERÊNCIAS}

Almerie MQ, Kerrigan DD. The association between obesity and poor outcome after COVID-19 indicates a potential therapeutic role for montelukast. Med Hypotheses. 2020 Oct;143:109883. doi: 10.1016/j.mehy.2020.109883. Epub 2020 May 27. PMID: 32492562; PMCID: PMC7255216. 
Badawi A, Ryoo SG. Prevalence of comorbidities in the Middle East respiratory syndrome coronavirus (MERS-CoV): a systematic review and meta-analysis. Int J Infect Dis. 2016 Aug;49:129-33. doi: 10.1016/j.ijid.2016.06.015. Epub 2016 Jun 21. PMID: 27352628; PMCID: PMC7110556.

Caci G, Albini A, Malerba M, Noonan DM, Pochetti P, Polosa R. COVID-19 and Obesity: Dangerous Liaisons. J Clin Med. 2020 Aug 4;9(8):2511. doi: 10.3390/jcm9082511. PMID: 32759719; PMCID: PMC7465218.

Celuppi, lanka Cristina et al. Uma análise sobre o desenvolvimento de tecnologias digitais em saúde para o enfrentamento da COVID-19 no Brasil e no mundo. Cadernos de Saúde Pública [online]. v. 37, n. 3 [Acessado 6 Setembro 2021], e00243220. Disponível em: <https://doi.org/10.1590/0102-311X00243220>. ISSN 1678-4464. https://doi.org/10.1590/0102-311X00243220.

Chiappetta S, Sharma AM, Bottino V, Stier C. Comunicação breve: COVID-19 e o papel da inflamação crônica em pacientes com obesidade. Int J Obes. 2020. https://doi.org/10.1038/s41366-020-0597-4 .

Chiappetta S, Sharma AM, Bottino V, Stier C. COVID-19 and the role of chronic inflammation in patients with obesity. Int J Obes (Lond). 2020 Aug;44(8):1790-1792. doi: 10.1038/s41366-0200597-4. Epub 2020 May 14. PMID: 32409680; PMCID: PMC7224343.

De Lorenzo A, Tarsitano MG, Falcone C, Di Renzo L, Romano L, Macheda S, Ferrarelli A, Labate D, Tescione M, Bilotta F, Gualtieri P. Fat mass affects nutritional status of ICU COVID-19 patients. J Transl Med. 2020 Aug 3;18(1):299. doi: 10.1186/s12967-020-02464-z. PMID: 32746930; PMCID: PMC7397427.

Foulkes AS, Selvaggi C, Shinnick D, Lumish H, Kim E, Cao T, Thaweethai T, Qian J, Lu F, Yan J, Cheng D, He W, Clerkin KJ, Madhavan MV, Meigs JB, Triant VA, Lubitz SA, Gupta A, Bassett IV, Reilly MP. Understanding the link between obesity and severe COVID-19 outcomes: Causal mediation by systemic inflammatory response. J Clin Endocrinol Metab. 2021 Sep 2:dgab629. doi: 10.1210/clinem/dgab629. Epub ahead of print. PMID: 34473294.

Frasca D, Reidy L, Cray C, Diaz A, Romero M, Kahl K, Blomberg BB. Influence of obesity on serum levels of SARS-CoV-2-specific antibodies in COVID-19 patients. PLoS One. 2021 Mar 24;16(3):e0245424. doi: 10.1371/journal.pone.0245424. PMID: 33760825; PMCID: PMC7990309.

Kim J, Na H, Kim JA, Nam JH. O que sabemos e o que precisamos saber sobre a obesidade induzida pelo adenovírus 36. Int J Obes. 2020. https://doi.org/10.1038/s41366-020-0536-4 .

Le Guen CL, King NA, Zhao H, Renza-Stingone EP, Gerhard GS, Soans RS. COVID-19 patients with obesity at risk for worse outcomes despite younger age and fewer inflammatory derangements. Surg Obes Relat Dis. 2021 Jun 24:S1550-7289(21)00303-8. doi: 10.1016/j.soard.2021.06.006. Epub ahead of print. PMID: 34353740; PMCID: PMC8223125. 
MACINKO, James et al . Prevalência e características de brasileiros com 50 anos ou mais que receberam um diagnóstico médico de COVID-19: iniciativa ELSI-COVID-19. Cad. Saúde Pública, Rio de Janeiro, v. 36, supl. 3, e00190320, 2020 . Disponível em $<$ http://www.scielo.br/scielo.php?script=sci_arttext\&pid=S0102-

$311 \times 2020001506002 \& \operatorname{lng}=p t \& n r m=i s o>$. acessos em 26 nov. 2020. Epub 13-Nov-2020. http://dx.doi.org/10.1590/0102-311x00190320.

Mejia, Fernando \& Medina, Carlos \& Cornejo, Enrique \& Morello, Enrique \& Vasquez, Sergio \& Alave, Jorge \& Schwalb, Alvaro \& Malaga, German. (2020). Características clínicas y factores asociados a mortalidad en pacientes adultos hospitalizados por COVID-19 en un hospital público de Lima, Perú.. 10.1590/SciELOPreprints.858. acesso n 28 Nov. 2020.

McGovern J, Dolan R, Richards C, Laird BJ, McMillan DC, Maguire D. Relation Between Body Composition, Systemic Inflammatory Response, and Clinical Outcomes in Patients Admitted to an Urban Teaching Hospital with COVID-19. J Nutr. 2021 Aug 7;151(8):2236-2244. doi: 10.1093/jn/nxab142. PMID: 34159388; PMCID: PMC8195217.

McNeill JN, Lau ES, Paniagua SM, Liu EE, Wang JK, Bassett IV, Selvaggi CA, Lubitz SA, Foulkes AS, Ho JE. The role of obesity in inflammatory markers in COVID-19 patients. Obes Res Clin Pract. 2021 Jan-Feb;15(1):96-99. doi: 10.1016/j.orcp.2020.12.004. Epub 2020 Dec 23. PMID: 33390322; PMCID: PMC7833898.

NUNES, Bruno Pereira et al. Multimorbidade e população em risco para COVID-19 grave no Estudo Longitudinal da Saúde dos Idosos Brasileiros. Cad. Saúde Pública, Rio de Janeiro , v. 36, n. 12, e00129620, 2020 Available from <http://www.scielo.br/scielo.php?script=sci_arttext\&pid=S0102311X2020001205003\&lng=en \&nrm=iso>. access on 26 Nov. 2020. Epub Nov 20, 2020. https://doi.org/10.1590/0102$311 \times 00129620$.

Razavi AC, Chang JL, Sutherland A, Niyogi A, Ménard GE. A 23-Year-Old Man With Multisystem Inflammatory Syndrome After Mild COVID-19. J Investig Med High Impact Case Rep. 2020 JanDec;8:2324709620974200. doi: 10.1177/2324709620974200. PMID: 33238745; PMCID: PMC7705768.

Santos E Silva JC, Vasconcelos AP, Noma IHY, Noronha NY, Aquino R, Giddaluru J, Durão L, CostaMartins AG, Schuch V, Moraes-Vieira PM, Nakaya HI. Gene signatures of autopsy lungs from obese patients with COVID-19. Clin Nutr ESPEN. 2021 Aug;44:475-478. doi: 10.1016/j.clnesp.2021.05.004. Epub 2021 May 26. PMID: 34330510; PMCID: PMC8149170.

STEELE, Eurídice Martínez et al . Mudanças alimentares na coorte NutriNet Brasil durante a pandemia de covid-19. Rev. Saúde Pública, São Paulo, v. 54, 91, 2020 . Available from <http://www.scielo.br/scielo.php?script=sci_arttext\&pid=S0034-

89102020000100266\&lng=en\&nrm=iso>. access on 27 Nov. 2020. Epub Sep 04, 2020. https://doi.org/10.11606/s1518-8787.2020054002950. 